\title{
Performance Evaluation of Novel M25 Green Concrete with GGBS, DRS and RCA Material-A Study Employing Response Surface Methodology
}

Prakash Chinnaiyan ( $\sim$ pen2prakash@gmail.com )

Amrita Vishwa Vidyapeetham https://orcid.org/0000-0003-2962-7846

Ananth Kumar

Amrita Vishwa Vidyapeetham

BharathKrishna Anuradha Chandrasekar

Amrita Vishwa Vidyapeetham

Malavika Sasi

Amrita Vishwa Vidyapeetham

Tejashwi Landu

Amrita Vishwa Vidyapeetham

\section{Research Article}

Keywords: Green concrete, Fresh and hard properties, Response surface plot, Response optimization, Regression analysis

Posted Date: June 18th, 2021

DOI: https://doi.org/10.21203/rs.3.rs-571748/v1

License: (c) (1) This work is licensed under a Creative Commons Attribution 4.0 International License. Read Full License 


\section{Abstract}

Global push for sustainability is increasing rapidly and countries are trying their best to become selfsustainable. Achieving a closed loop system in an industrial production has become a major objective in order to achieve self-sustainability and thus reducing the carbon footprint. Key aspect of a closed loop system includes reusing the byproducts and waste materials for a more productive process rather than dumping up in a landfill. In this study, waste and used materials like ground granulated blast slag (GGBS) up to $50 \%$, dolomite rock sand (DRS) up to $30 \%$ and recycled coarse aggregate (RCA) up to $30 \%$ were chosen as replacement for cement, fine aggregate and coarse aggregate respectively for the making of novel M25 grade green concrete. Concrete properties viz., slump, compressive strength, split tensile strength and flexural strength were tested and corresponding regression models were developed. The developed models were used to obtain optimum percentage addition of GGBS (>20\%), DRS (>9\%) and RCA ( $<17 \%)$ for achieving M25 grade strength. Further an increase of GGBS to $50 \%$, DRS to $30 \%$ and with elimination of RCA, the compressive strength increased by $59 \%$ (39.7 MPa), Split tensile increased by $23 \%$ (4.3 MPa) and flexural strength increased by $19 \%$ (4.2 MPa) in comparison to $\mathrm{M} 25$ concrete. The study found that the waste materials can be sustainably used to prepare novel M25 green concrete which achieved higher strength than conventional concrete, thus reducing the cost of concrete and with reduced carbon footprint on the environment.

\section{Introduction}

Concrete, a composite material is used extensively for construction activities. Countries all over the world are on the surge of improving their infrastructure and heavily rely on concrete. This creates a huge demand of the raw materials used in concrete such as cement, crushed sand and natural aggregates (Soundara B et al 2015; Vasudevan Mangottiri et al 2020). Researchers are constantly investigating for alternative sustainable materials that can be made used off in concrete without compromising its quality (Cai G 2016; Wałach D 2019; Esparza LA 2020). Use of by products and waste materials could be a sustainable approach (Bhuvaneshwari S et al 2014; Pillai RJ 2019; Preethi V et al 2020). Widely studied material for replacement of cement includes ground granulated blast slag (GGBS) which is a by-product of iron and steel industry. In case of mass concreting, the amount of heat generated becomes a major issue and this could be reduced by using mineral admixtures GGBS, in addition to improvement in physical properties of concrete (Alawad et al 2015; Hawileh et al 2017). Literature indicates that though the initial rate of strength gain of concrete with GGBS is comparatively less, it matches with the strength of a conventional concrete mix with OPC grade cement after 28 days (Phul et al 2019). In a study it was found that GGBS can be used up to $40 \%$ replacement of cement which improves the concrete strength. The study also confirmed that the usage of GGBS in concrete improves its flow-ability in plastic stages (Mo et al 2015).

River sand, the commonly used fine aggregate is a non renewable resource but its demand is exponentially increasing and as a result causing serious environmental issues (Scrivener et al 2015). Many countries have limited the use of river sand in construction and therefore the construction 
industries are opting for alternative materials including crushed sand (Ananthkumar et al 2020; Lalith Prakash et al 2021) and dolomite rock sand (DRS). DRS is a finely powered crystalline silica and is a byproduct from cement manufacturing industries through the beatification process of limestone using silica as raw material. From literature it was inferred that DRS can replace sand till $30 \%$. When the $\%$ addition of DRS is greater than $30 \%$, the amount of water available for hydration is reduced and results in shrinkage and reduction in strength (Chinnaraju et al 2013; Nandakumar et al 2017; Landu et al 2020).

Coarse aggregates have a major role on the strength property of concrete and take up a major part of the load that occurs on the concrete structures. Once the building is no longer serviceable, it is demolished and the wastes are disposed in landfills. According to a research work more than twenty thousand tons of C\& D wastes (Construction and demolition) are piled up everyday (Al-Ansary 2013). Incorporating recycled coarse aggregate in concrete (RCA) helps in achieving closed loop system in the construction industry and reduces the demand on fresh coarse aggregates. Replacement of RCA up-to $30 \%$ does not affect the strength and durability of concrete. (Zheng et al 2018). Studies have shown that RCA is generally porous in nature and higher percentage replacement decreases the strength which can be attributed to the weak residual mortar layer, and also the characteristics of RCA obtained from the construction and demolition site. It was reported that concrete slump and strength decreased as more RCA was added for natural aggregates (Heidari A 2018; Tufail et al 2020). In studies conducted by Chakradhara Rao M (2018) found that the compressive strength reduces by $20 \%$ for complete RCA replacement. Hadavand (2019) in his studies have shown that on using RCA in a repeated fashion show that the strength parameters decrease over successive usage in concrete, though it makes the mix more economical. Further it was found that 20 to $40 \%$ replacement with RCA helped to achieve good workability, and at $60 \%$ replacement, the compressive strength was maximum and then decreased progressively.

Design of Experiments (DoE) using RSM (response surface methodology) is commonly used in the recent days to optimize the independent variables (factors) for improving the output (response) of any experimental setup by developing and analysing regression models (Hilal N 2021; Boukli et al 2015). It also reduces the cost of the project by reducing the number of experimental trials especially when there are a greater number of independent variables (factors) (Chinnaiyan et al 2019; Senthil Kumar et al 2014). RSM was commonly employed Concrete for instance is highly unpredictable as it's a culmination of different materials having different properties. Developing a model helps in analyzing the relationship between various factors and the response. Studies on effects of fibres, cement and water on flexural and compressive strength of high strength concrete and concrete pavement were conducted using RSM and optimum quantities were evaluated(Mardani et al 2015; Rooholamini et al 2018).

In this study, sustainable materials like ground granulated blast slag (GGBS), dolomite rock sand (DRS) and recycled coarse aggregate (RCA) were chosen as replacement for cement, fine and coarse aggregate respectively. Regression models was developed involving the use of above materials in concrete and their impact on the strength parameters viz., compressive, flexure and split tensile was studied employing response surface methodology. 


\section{Methodologies}

\subsection{Materials}

Cement (OPC 53 grade), crushed sand $(<4.75 \mathrm{~mm})$, coarse aggregate $(20 \mathrm{~mm}), \mathrm{RCA}(20 \mathrm{~mm})$, were all procured from local suppliers. GGBS was procured from India Mart. DRS was obtained from ACC cement manufacturing industry, Coimbatore, India. The tests on the materials employed in this study were carried out as per BIS standards and their results are tabulated (Table 1).

Table 1

Properties of materials used in the study.

\begin{tabular}{|c|c|c|}
\hline \\
\hline Materials & Properties & Results \\
\hline \multirow[t]{2}{*}{ Cement (OPC grade 53) } & Specific gravity & 3.16 \\
\hline & Consistency & $29 \%$ \\
\hline Ground Granulated Blast Slag (GGBS) & Specific gravity & 2.9 \\
\hline \multirow[t]{4}{*}{ Crushed Sand } & Specific gravity & 2.72 \\
\hline & Water Absorption & $3 \%$ \\
\hline & Zone & 2 \\
\hline & Fineness modulus & 2.3 \\
\hline \multirow[t]{4}{*}{ DRS } & Specific gravity & 2.67 \\
\hline & Fineness modulus & 1.95 \\
\hline & Water Absorption & $3.7 \%$ \\
\hline & Zone & 3 \\
\hline \multirow[t]{3}{*}{ Coarse aggregate } & Specific gravity & 2.74 \\
\hline & Nominal Size & $20 \mathrm{~mm}$ \\
\hline & Water Absorption & $0.4 \%$ \\
\hline \multirow[t]{3}{*}{ RCA } & Specific gravity & 2.64 \\
\hline & Nominal Size & $20 \mathrm{~mm}$ \\
\hline & Water Absorption & $4 \%$ \\
\hline
\end{tabular}

\subsection{Design Mix}

Design mix for control sample corresponding to a compressive strength of $25 \mathrm{~N} / \mathrm{mm}^{2}$, according to IS 10262:2019, and the mix was designed for $100 \mathrm{~mm}$ slump, with the use of OPC grade 53 cement. For replacement with various materials, the combined specific gravity of the materials was found and the 
quantities of materials were expressed by absolute volume method. The water correction was calculated and the quantity of water added to the mix was corrected accordingly based on results of water absorption and the $\mathrm{w} / \mathrm{c}$ ratio was chosen as 0.5 . The quantities of materials used include cement $=396$ $\mathrm{kg} / \mathrm{m}^{3}, \mathrm{FA}=718 \mathrm{~kg} / \mathrm{m}^{3}, \mathrm{CA}=1075 \mathrm{~kg} / \mathrm{m}^{3}$ and Water $=198 \mathrm{~kg} / \mathrm{m}^{3}$ and percentage replacements of materials were calculated accordingly.

\subsection{Design of Experiment}

Design of experiments employing RSM was chosen for this study. Replacement of different sustainable materials in concrete was performed and the performance evaluation of sustainable concrete was studied. The three factors chosen for replacement include GGBS \% replacement by weight of cement $\left(\mathrm{X}_{1}\right)$ in the range of 0 to $50 \%$, DRS \% replacement by weight of fine aggregate $\left(X_{2}\right)$ in the range of 0 to $30 \%$, recycled coarse aggregate \% replacement by weight of coarse aggregate $\left(X_{3}\right)$ in the range of 0 to $30 \%$. MINITAB software was employed for generating experimental run orders and for further regression analysis. A total of 20 experiments were designed using MINITAB software and are presented (Table S1, Table S1 to S5 are shown in supplementary material). Slump and the strength parameters viz., compressive, flexural and tensile strength were chosen as the responses for testing the performance of the concrete. These responses were further inputted into MINITAB software for further regression analysis.

\section{Results And Discussions}

\subsection{Evaluation of fresh and hardened properties of sustainable concrete}

Experiments were performed for various run orders and concrete specimens were evaluated for slump and other 3 strength parameters by following standard experimental procedure. For each of the four properties (responses) of any run order three trials were conducted in addition to separate control specimens. The mean values for each property after the necessary control corrections are calculated and reported (Table 2). It was observed that slump $(\mathrm{mm})$ varied between 69 and 140, compressive strength $\left(\mathrm{N} / \mathrm{mm}^{2}\right)$ between 16.3 and 39.78, split tensile strength $\left(\mathrm{N} / \mathrm{mm}^{2}\right)$ between 2.6 and 4.3 , and flexural strength $\left(\mathrm{N} / \mathrm{mm}^{2}\right)$ between 2.95 and 4.16 for the various run orders. 
Table 2

Results of fresh \& hard property tests of concrete.

\begin{tabular}{|llllllll|}
\hline Run & $\begin{array}{l}\text { GGBS } \\
\text { order }\end{array}$ & $\begin{array}{l}\text { DRS } \\
(\%)\end{array}$ & $\begin{array}{l}\text { RCA } \\
(\%)\end{array}$ & Slump(mm) & $\begin{array}{l}\text { Compressive } \\
\text { strength } \\
\left(\mathbf{N} / \mathbf{m m}^{2}\right)\end{array}$ & $\begin{array}{l}\text { Flexural } \\
\text { Strength }\end{array}$ & $\begin{array}{l}\text { Split tensile } \\
\text { Strength }\end{array}$ \\
\hline 1 & 0 & 0 & 0 & 86 & 27.2 & 3.60 & 3.56 \\
\hline 2 & 25 & 15 & 15 & 92 & 29.4 & 3.65 & 3.65 \\
\hline 3 & 0 & 0 & 30 & 69 & 16.3 & 2.95 & 2.60 \\
\hline 4 & 0 & 15 & 15 & 83 & 28.7 & 3.38 & 3.52 \\
\hline 5 & 25 & 15 & 15 & 94 & 29.56 & 3.63 & 3.72 \\
\hline 6 & 50 & 0 & 30 & 76 & 18.23 & 3.32 & 3.30 \\
\hline 7 & 0 & 30 & 0 & 132 & 35.6 & 3.93 & 4.24 \\
\hline 8 & 25 & 0 & 15 & 89 & 28.2 & 3.62 & 3.57 \\
\hline 9 & 25 & 15 & 15 & 95 & 29.62 & 3.59 & 3.69 \\
\hline 10 & 50 & 30 & 30 & 81 & 21.23 & 3.69 & 3.42 \\
\hline 11 & 50 & 15 & 15 & 99 & 33.12 & 3.79 & 4.00 \\
\hline 12 & 25 & 15 & 15 & 95 & 29.67 & 3.60 & 3.53 \\
\hline 13 & 50 & 0 & 0 & 91 & 37.4 & 3.82 & 4.12 \\
\hline 14 & 50 & 30 & 0 & 140 & 39.78 & 4.16 & 4.30 \\
\hline 15 & 25 & 15 & 15 & 93 & 29.33 & 3.62 & 3.45 \\
\hline 16 & 0 & 30 & 30 & 80 & 20.78 & 3.33 & 3.49 \\
\hline 17 & 25 & 30 & 15 & 104 & 30.45 & 3.84 & 3.75 \\
\hline 18 & 25 & 15 & 0 & 99 & 28.2 & 3.73 & 4.09 \\
\hline 19 & 25 & 15 & 15 & 93 & 28.67 & 3.65 & 3.65 \\
\hline 20 & 25 & 15 & 30 & 78 & 20.32 & 3.38 & 3.40 \\
\hline 32 & & & & & & \\
\hline
\end{tabular}

\subsection{Regression analysis and modeling}

The experimental results of various run order were inputted to MINITAB software and standard regression analysis was done for slump and other 3 strength parameters (Table S2 to S5 respectively in supplementary material). In this study, for all statistical analysis a confidence level of $95 \%$ was considered. Zhang et al (2020) used a regression model that was developed over two step iterations by considering only the significant factors (significant factors are those terms for which the $p$ value $<0.1$ ) 
which influences the response. Accordingly, the model equations were constructed for each of the four chosen properties viz., slump (Eq. 1), compressive strength (Eq. 2), split tensile strength (Eq. 3) and flexural strength (Eq. 4) respectively. have incorporated in their studies that there are two main sections of parametric hypothesis tests employed in the model. Statistical t-test for analysing the regression coefficients, ANNOVA (F-test) for evaluating the overall fit of the mode was used (Simsek et al 2018; Sultana et al 2020; Zhang et al 2020).

The model summary for the four properties of sustainable concrete is tabulated in Table 3 . The $S$ value which stands for standard error of regression indicates the closeness of the observed values to the regression line. $R^{2}$ is a statistical measure which ranges from 0 to $100 \%$, where $100 \%$ indicates that the model explains all the variability of the response data. $R^{2}$ (pred) indicates the predicting capability of the model. In general, for all the models an $R^{2}$ value of $>93 \%\left(R^{2}\right.$ adj $\left.>91 \%\right)$ was observed. This indicates that almost $90 \%$ of the variation of slump and the other strength parameters of sustainable concrete can be explained by the combination of the chosen three factors by the developed regression models. Further the higher $\mathrm{R}^{2}$ indicates that the model obtained is a good predictor of the chosen response and it can be used for optimizing the different properties of sustainable concrete within the boundary conditions.

Table 3

Model summary of fresh and hardened properties of sustainable concrete.

\begin{tabular}{|lllll|}
\hline Parameter & \multicolumn{3}{l|}{ Model summary } & \\
\cline { 2 - 5 } & S & R-sq & R-sq(adj) & R-sq(pred) \\
\hline Slump & 4.39 & $95.09 \%$ & $93.33 \%$ & $89.56 \%$ \\
\hline Compressive strength & 1.76 & $94.36 \%$ & $91.76 \%$ & $80.41 \%$ \\
\hline Split tensile strength & 0.11 & $93.75 \%$ & $92.08 \%$ & $89.74 \%$ \\
\hline Flexural strength & 0.06 & $96.86 \%$ & $95.41 \%$ & $91.22 \%$ \\
\hline
\end{tabular}

\subsubsection{Slump}

Using Eq. (1) pareto chart (Fig. 1) and the contour plots (Fig. 2a - 2c) were generated for slump. It was found that the use of GGBS and DRS increases the workability and RCA reduces the same. It can be inferred from pareto chart of slump that RCA (factor $C$ ) is a significant parameter which influences the slump model followed by GGBS and DRS replacements. Further the combination of DRS and RCA plays a positive role in slump. In general, it was observed that there is an increase in workability in DRS incorporated concrete up to $35 \%$, for $30 \%$ DRS replacement which is due to the ball bearing effect imparted by it. (Fig. 2c). With an increase in RCA, the slump falls below $80 \mathrm{~mm}$, which is due to the porous nature of the aggregates. It was observed that RCA replacement up to $15 \%$ can produce a 
workable slump and further increase, drastically reduces the slump. Further, the combination of RCA (up to $15 \%$ ) and DRS (up to $30 \%$ ) positively influences the slump. (Fig. 1).$$
\operatorname{Slump}(\mathrm{mm})=85.03+0.1480 \text { GGBS }+1.138 \text { DRS }-0.435 R C A+0.01200 \text { DRS } \times \text { DRS }
$$ Slump $(m$$$
-0.04389 D R S \times R C A
$$

\subsubsection{Compressive strength}

Using Eq. (2) pareto chart (Fig S1, Fig S1 to S6) and the contour plots (Fig S2a - S2c) were generated for compressive strength. In general, use of GGBS and DRS increases the compressive strength and RCA reduces the same. Referring Fig S1, influence of RCA in the obtained model is major followed by GGBS and DRS. The contour plots show the variation of materials used and their impact on the compressive strength. It was inferred that a compressive strength of $25 \mathrm{MPa}$ (as that of control specimen) could be achieved with GGBS replacement of $20 \%$ and DRS replacement of $15 \%$, making the concrete more economical using sustainable materials. Further increase of GGBS to $50 \%$ and DRS to $30 \%$ increases the compressive strength by $59 \%$ and a maximum compressive strength of $39.7 \mathrm{MPa}$ was achieved (Fig S2). High strength obtained is due to the micro filler effect of DRS. Further addition of GGBS to the mix makes it stronger than conventional concrete (Hawileh et al 2017). If required to make the mix more economical, incorporation of RCA can also be considered for structures which might requires a less compressive strength like paver blocks and in other secondary construction activities.

\section{Compressive strength $\left(\mathrm{N} / \mathrm{mm}^{2}\right)$ \\ $=28.40-0.0294 G G B S+0.1367 D R S+0.221 R C A+0.00348 G G B S$ \\ $\times$ GGBS $-0.01989 R C A \times R C A-0.00400 G G B S \times R C A$}

\subsubsection{Split Tensile strength:}

Using Eq. (3) pareto chart (Fig S3) and the contour plots (Fig S4a - S4c) were generated for split tensile strength. Similar to other strength parameter, use of GGBS and DRS increases the tensile strength and RCA reduces the same. Influence of RCA in the obtained model is major followed by GGBS and DRS. A split tensile strength of $3.5 \mathrm{MPa}$ could be achieved with GGBS replacement of $25 \%$ and DRS replacement of $17 \%$ when compared to conventional concrete and further increase of GGBS to $50 \%$ and DRS to $30 \%$ increases the split tensile strength by $23 \%$ to $4.3 \mathrm{MPa}$ (Fig S4).

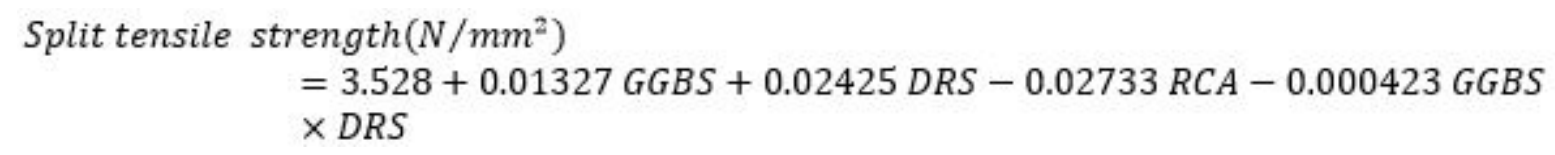

\subsubsection{Flexural Strength}

Using Eq. (4) pareto chart (Fig S5) and the contour plots (Fig S6 a - S6c) were generated for flexural strength. In general, use of GGBS and DRS increases the flexural strength and RCA reduces the same. Influence of RCA in the obtained model is major followed by DRS and GGBS. It was found that a flexural strength of $3.5 \mathrm{MPa}$ could be achieved with GGBS replacement of $30 \%$ and DRS replacement of $25 \%$ 
when compared to conventional concrete and further increase of GGBS to $50 \%$ and DRS to $30 \%$ increases the flexural strength by $19 \%$ and a maximum flexural strength of $4.2 \mathrm{MPa}$ was achieved (Fig S6).

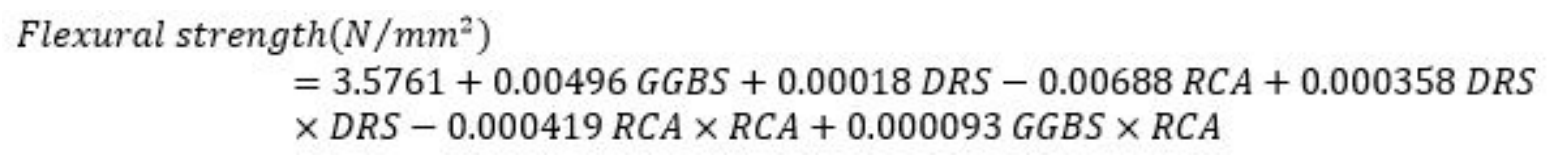

\subsection{Optimization}

The optimisation of the factors was performed employing the response optimiser tool of MINITAB. Optimum condition considering the slump $80 \mathrm{~mm}$, compressive strength $25 \mathrm{~N} / \mathrm{mm}^{2}$, split strength 3.5 $\mathrm{N} / \mathrm{mm}^{2}$ and flexural strength $3.5 \mathrm{~N} / \mathrm{mm}^{2}$ were obtained (Fig. 3). From Fig. 3, the optimal composite desirability (D) was obtained by taking the average of the individual composite desirability of the chosen factors. The value of $D$ varies from 0 to 1 , where the value closer to 1 is taken as the most feasible process. It can be inferred that in order to achieve an M25 grade concrete the required quantities of GGBS, DRS and RCA replacements are $20.09 \%, 9.68 \%$ and $17.24 \%$ by weight respectively.

RCA was found to have a negative effect on the strength parameters. The decrease of strength due to increase of RCA is due to its porous nature and its low crushing strength (Chakradhara Rao et al 2018). Complete elimination of RCA replacement resulted in increase in strength parameters. With zero replacement of RCA, and GGBS replacement of $50 \%$, and DRS $30 \%$ replacement, it was found that maximum compressive $\left(39.7 \mathrm{~N} / \mathrm{mm}^{2}\right)$, tensile $\left(4.3 \mathrm{~N} / \mathrm{mm}^{2}\right)$ and flexural strength $\left(4.2 \mathrm{~N} / \mathrm{mm}^{2}\right)$ was achieved. Micro filling of GGBS and DRS, which leads to effective filling up of the voids in the concrete leads to an increased strength. The performance of concrete exceeds expectations for a mix including $50 \%$ GGBS and 30\% DRS and 0\% RCA by weight. Experiments for validation were performed under the optimum condition and the various parameters were tested (Table 4). It is observed that the difference between predicted value and observed values of slump, compressive, flexural strength and split tensile strength is observed to be $<10 \%$, thereby proving the correctness of the model.

Table 4

Observed and predicted values for the optimum replacements of GGBS, DRS and RCA

\begin{tabular}{|lllll|}
\hline $\begin{array}{l}\text { Material replacements for Cement, FA } \\
\text { and CA (\%) in M25 concrete }\end{array}$ & Property & $\begin{array}{l}\text { Observed } \\
\text { value (\%) }\end{array}$ & $\begin{array}{l}\text { Predicted } \\
\text { value (\%) }\end{array}$ & $\begin{array}{l}\text { \% change } \\
\text { from actual }\end{array}$ \\
\hline GGBS: $20.09 \%$ & Slump & 84 & 80 & 4.7 \\
DRS: $9.68 \%$ & $\begin{array}{l}\text { Compressive } \\
\text { strength }\end{array}$ & 27 & 28.5 & 5.26 \\
RCA: $17.24 \%$ & $\begin{array}{l}\text { Split tensile } \\
\text { strength }\end{array}$ & 3.5 & 3.53 & 0.8 \\
\hline $\begin{array}{l}\text { Flexural } \\
\text { strength }\end{array}$ & 3.5 & 3.67 & 4.6 \\
\hline
\end{tabular}




\section{Conclusions}

In this study, byproduct waste materials such as GGBS, DRS and RCA were experimented as alternative replacements for cement, fine aggregate, and coarse aggregate respectively for producing a novel M25 grade green concrete. To optimize the percentage of materials replaced in concrete, a response surface model was developed using MINITAB software. A total of 20 different experimental run order were tested for slump, compressive, split tensile and flexural strength and regression models were developed with high R-sq (adj) values (>90\%). Slump value is higher for DRS replaced concrete, due to the ball bearing effect of dolomite rock sand. Thus, incorporating DRS improves the workability of the concrete mix. M25 grade concrete properties can be achieved with replacement of conventional materials with GGBS (20.09 $\%)$, DRS (9.68\%) and RCA (17.24\%) by weight respectively. Increase of RCA above 17\% leads to reduction of strength in concrete due to its porous nature and poor inter-locking properties, although $<17 \%$ RCA replacement for CA can be considered for secondary construction activities. A considerable increase in strength was observed with the increase in percentage of replacement with GGBS and DRS and without RCA replacements. Maximum strength were obtained for the mix with 50\% GGBS, 30\% DRS and 0\% RCA which resulted in a compressive strength of $39.7 \mathrm{MPa}$, split tensile strength of $4.3 \mathrm{MPa}$, and a flexural strength of 4.2 MPa. Micro-filling effect and better hydration results in increased strength with the increase in percentage of replacement with GGBS and DRS. The use of GGBS can help reduce the $\mathrm{CO}_{2}$ emissions and also make way for applications in mass concreting. The results obtained in this study illustrate the possibility of using by products from industries as potential ingredients in making a novel M25 grade green concrete which exhibits higher strength than the conventional concrete. This study helps to achieve a more sustainable construction practices at reduced cost, without compromising its strength parameters

\section{Declarations}

\section{Acknowledgements}

This research work was supported by the Amrita funding grant IFRP/PPCP/30.

Ethics approval and consent to participate : Not applicable

Consent for publication : Not applicable

Availability of data and materials : All data generated or analyzed during this study are included in this article and its supplementary information files

Competing interests : The authors declare that they have no competing interests

Funding: This research work was supported by the Amrita funding grant IFRP/PPCP/30.

Authors' contributions : 
Dr. C. Prakash and Mr. M. Ananthkumar contributed to the study conception and design. Material preparation, experiments and data collection were performed by A C Bharath Krishnaa, Malavika Sasi and L Tejashwi. Data analysis and discussion were performed by Dr. C. Prakash and A C Bharath Krishnaa . Supervision and validation was done by Dr. C. Prakash and Mr. M. Ananthkumar. The first draft of the manuscript was written by A C Bharath Krishnaa and Dr.C.Prakash and all authors have subsequently contributed for the improvement of the manuscript. All authors read and approved the final manuscript.

\section{References}

1. Alawad OA, Alhozaimy A, Jaafar MS et al (2015) Effect of Autoclave Curing on the Microstructure of Blended Cement Mixture Incorporating Ground Dune Sand and Ground Granulated Blast Furnace Slag. International Journal of Concrete Structures Materials 9:381-390. https://doi.org/10.1007/s40069-015-0104-9

2. Al-Ansary, lyengar SR (2013) Physiochemical characterization of coarse aggregates in Qatar for construction industry. International Journal of Sustainable Built Environment 2(1):27-40. https://doi.org/10.1016/j.ijsbe.2013.07.003

3. Ananthkumar M, Mini KM, Prakash C et al (2020) Study on the efficiency of CFRP and GFRP in corrosion resistance of rebar embedded in concrete. IOP Conference Series: Materials Science and Engineering 872(1) 012137. https://doi.org/10.1088/1757-899X/872/1/012137

4. Bhuvaneshwari S, Robinson RG, Gandhi SR (2014) Behaviour of Lime Treated Cured Expansive Soil Composites. Indian Geotech J 44:278-293. https://doi.org/10.1007/s40098-013-0081-3

5. Boukli Hacene, Ghomari F, Schoefs F et al (2014) Probabilistic Modelling of Compressive Strength of Concrete Using Response Surface Methodology and Neural Networks. Arab J Sci Eng 39:4451-4460. https://doi.org/10.1007/s13369-014-1139-y

6. Cai G, Noguchi T, Degée H et al (2016) Volcano-related materials in concretes: a comprehensive review. Environ Sci Pollut Res 23:7220-7243. https://doi.org/10.1007/s11356-016-6161-z

7. Chinnaraju K, Ramkumar, Lineesh, Nithya, Sathish V (2013) Study on concrete using steel slag as coarse aggregate replacement and ecosand as fine aggregate replacement. International Journal of Research in Engineering Advanced Technology 1:52-61

8. Chinnaiyan P, Thampi SG, Kumar M, Balachandran M (2019) Photocatalytic treatment of amiodarone and levetiracetam in pharmaceutical industry effluent: Process optimization using response surface methodology. Desalination and Water Treatment 170: 253-264. https://doi.org/10.5004/dwt.2019.24727

9. Chakradhara Rao M (2018) Properties of recycled aggregate and recycled aggregate concrete: effect of parent concrete. Asian J Civ Eng 19:103-110. https://doi.org/10.1007/s42107-018-0011-x

10. Esparza LA, Ossa A, Botero E (2020) Evaluation of the complex dynamic modulus of asphaltic concretes manufactured with construction and demolition waste (CDW) aggregates. Environ Sci Pollut Res 27:11575-11586. https://doi.org/10.1007/s11356-020-07727-2 
11. Hadavand B, Imaninasab R (2019) Assessing the influence of construction and demolition waste materials on workability and mechanical properties of concrete using statistical analysis. Innov Infrastruct Solut 4 (29). https://doi.org/10.1007/s41062-019-0214-3

12. Hawileh R, Abdalla JA, Fardmanesh F, Shahsana P, Khalili A (2017) Performance of reinforced concrete beams cast with different percentages of GGBS replacement to cement. Archives of Civil Mechanical Engineering 17:511-519. https://doi.org/10.1016/j.acme.2016.11.006

13. Heidari A, Hashempour $M$, Javdanian $H$ et al (2018) Investigation of mechanical properties of mortar with mixed recycled aggregates. Asian J Civ Eng 19:583-593. https://doi.org/10.1007/s42107-0180044-1

14. Hilal N, Hadzima-Nyarko M (2021) Improvement of eco-efficient self-compacting concrete manufacture by recycling high quantity of waste materials. Environ Sci Pollut Res. https://doi.org/10.1007/s11356-021-14222-9

15. Mardani Aghabaglou A, Tuyan M, Ramyar K (2015) Mechanical and durability performance of concrete incorporating fine recycled concrete and glass aggregates. Mater Struct 48:2629-2640. https://doi.org/10.1617/s11527-014-0342-3

16. Mo KH, Alengaram UJ, Jumaat MZ (2015) Utilization of ground granulated blast furnace slag as partial cement replacement in lightweight oil palm shell concrete. Mater Struct 48:2545-2556. https://doi.org/10.1617/s11527-014-0336-1

17. Nandakumar P, Senthil Kumar V (2017) A study on recycled coarse aggregate concrete using ecosand as fine aggregate. International journal of Civil Engineering Technology 8(9):638-647

18. Landu T, Ananthkumar M, Prakash C, Bharath Krishna, Sasi M (2020) Dolomite rock sand as fine aggregate replacement in construction activities: A comparative study. Materials Today Proceedings. https://doi.org/10.1016/j.matpr.2020.10.678

19. Lalith Prakash, Chinnaiyan P et al ( (2021) Study on Performance of Concrete Made with Copper Slag and Mineral Admixtures. Lecture Notes in Civil Engineering 97:917-928. https://doi.org/10.1007/978-3-030-55115-5_82 )

20. Pillai RJ et al (2019) Behaviour Thresholds of Quarry Dust-Bentonite Mixes. Geotechnical Characterisation and Geoenvironmental Engineering, Lecture Notes in Civil Engineering 16. https://doi.org/10.1007/978-981-13-0899-4_29

21. Preethi $V$ et al (2020) Enhancing biohydrogen production from sugar industry wastewater using metal oxide/graphene nanocomposite catalysts in microbial electrolysis cell. Int J Hydrogen Energy 45(13):7647-7655. https://doi.org/10.1016/j.ijhydene.2019.09.068

22. Phul AA, Memon MJ, Shah SNR, Sandhu AR (2019) GGBS and fly ash effects on compressive strength by partial replacement of cement concrete. Civil Engineering Journal 5(4):913-921

23. Rooholamini H, Hassani A, Aliha MRM (2018) Evaluating the effect of macro-synthetic fibre on the mechanical properties of roller-compacted concrete pavement using response surface methodology. Constr Build Mater 159:517-529. https://doi.org/10.1016/j.conbuildmat.2017.11.002 
24. Scrivener KL, Lothenbach B, De Belie N et al (2015) TC 238-SCM: hydration and microstructure of concrete with SCMs. Mater Struct 48:835-862. https://doi.org/10.1617/s11527-015-0527-4

25. Senthil Kumar K, Baskar K (2014) Response surfaces for fresh and hardened properties of concrete with e-waste (HIPS). Journal of Waste Management. 517219. https://doi.org/10.1155/2014/517219

26. Şimşek B, Uygunoğlu T, Korucu H, Kocakerim MM (2018) Analysis of the effects of dioctyl terephthalate obtained from polyethylene terephthalate wastes on concrete mortar: A response surface methodology based desirability function approach application. J Clean Prod 170:437-445

27. Soundara B et al (2015) Effect of Steel Fiber on High Performance Concrete Subjected to Heating. International Journal of Applied Engineering Research 10(13):33419-33423

28. Sultana N, Hossain SZ, Alam MS, Hashish MMA, Islam MS (2020) An experimental investigation and modeling approach of response surface methodology coupled with crow search algorithm for optimizing the properties of jute fiber reinforced concrete. Constr Build Mater 243:118216. https://doi.org/10.1016/j.conbuildmat.2020.118216

29. Raghu P, Pillai RJ (2019) Behaviour Thresholds of Quarry Dust-Bentonite Mixes. Geotechnical Characterisation and Geoenvironmental Engineering, Lecture Notes in Civil Engineering 16. https://doi.org/10.1007/978-981-13-0899-4_29

30. Tufail RF, Feng $X$, Zahid $M$ et al (2020) Statistical modeling of rubberized concrete beams confined by FRP using RSM technique. Sādhanā 45:113. https://doi.org/10.1007/s12046-020-01349-7

31. Vasudevan, Mangottiri et al ( (2020) A Sustainable Approach to the Prevalent Problems in Tactical Urban Construction of Temporary Structures. IOP Conf Ser: Mater Sci Eng 955:012013)

32. Wałach D, Dybeł $P$, Sagan J et al (2019) Environmental performance of ordinary and new generation concrete structures-a comparative analysis. Environ Sci Pollut Res 26:3980-3990. https://doi.org/10.1007/s11356-018-3804-2

33. Zheng C, Lou C, Du G, Li X, Liu Z, Li L (2018) Mechanical properties of recycled concrete with demolished waste concrete aggregate and clay brick aggregate. Results in Physics 9:1317-1322. https://doi.org/10.1016/j.rinp.2018.04.061

34. Zhang Q, Feng X, Chen X, Lu K (2020) Mix design for recycled aggregate pervious concrete based on response surface methodology. Constr Build Mater 259:119776. https://doi.org/10.1007/s40069012-0024-x

\section{Figures}




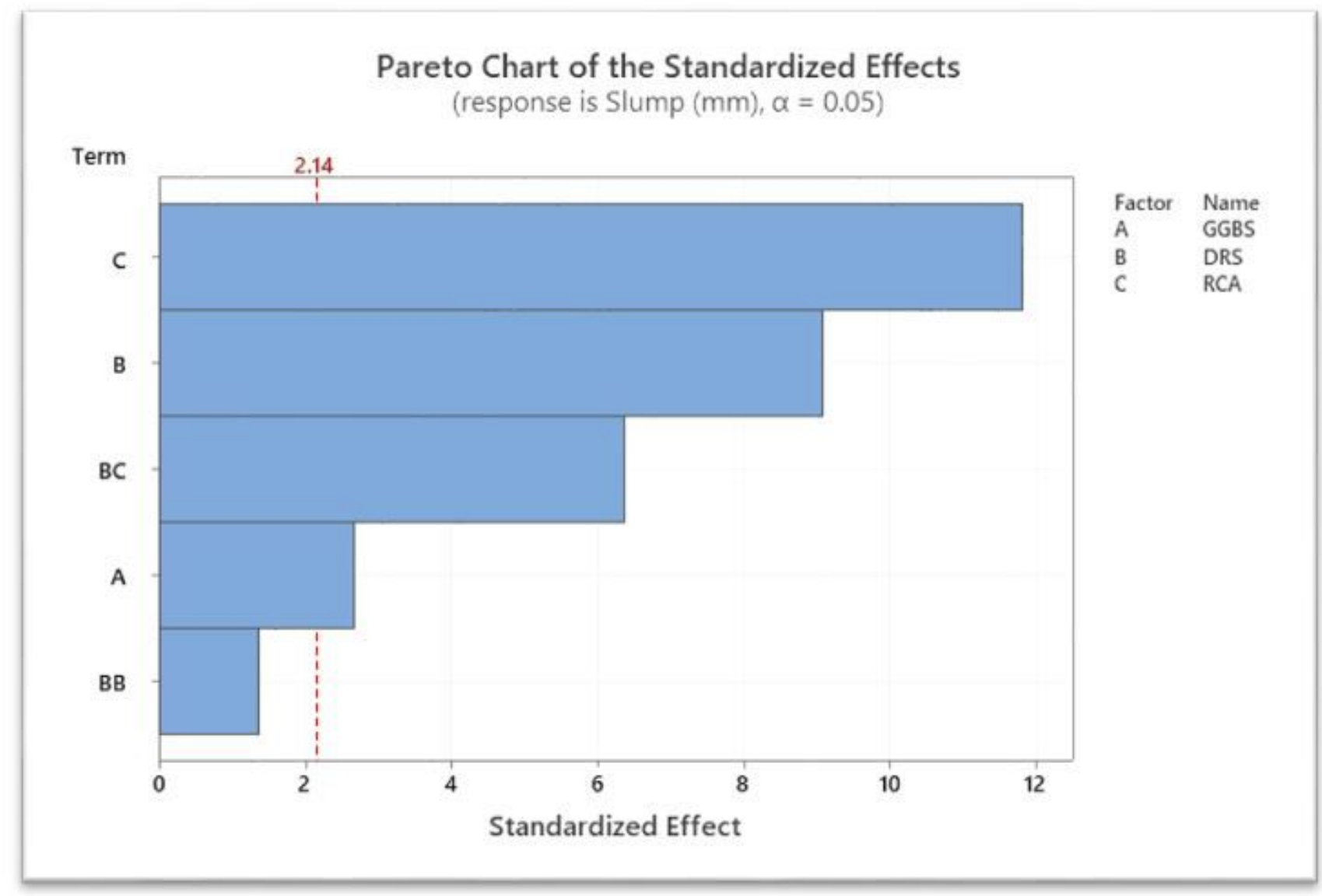

Figure 1

Pareto Chart of the standardised effects(slump). 


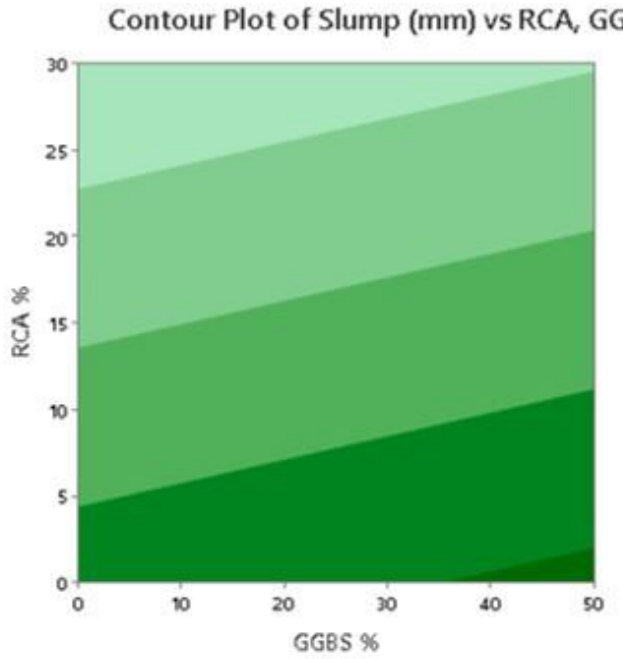

Fig 2 (a)
Contour Plot of Slump (mm) vs DRS, GGBS

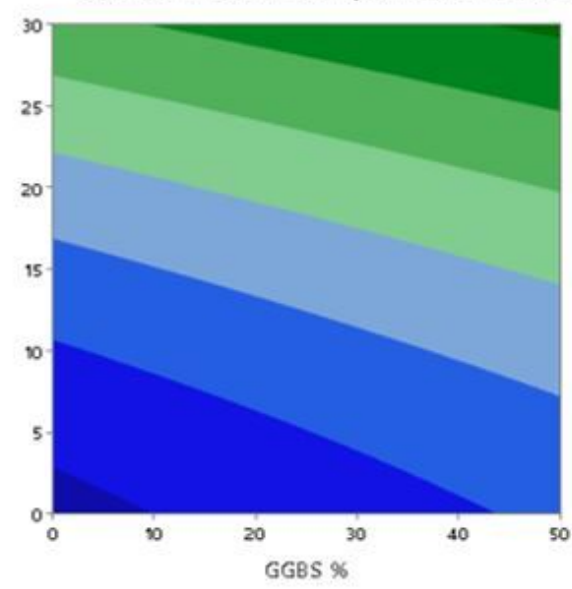

Fig 2(b)

Contour Plot of Slump ( $\mathrm{mm})$ vs RCA, DRS
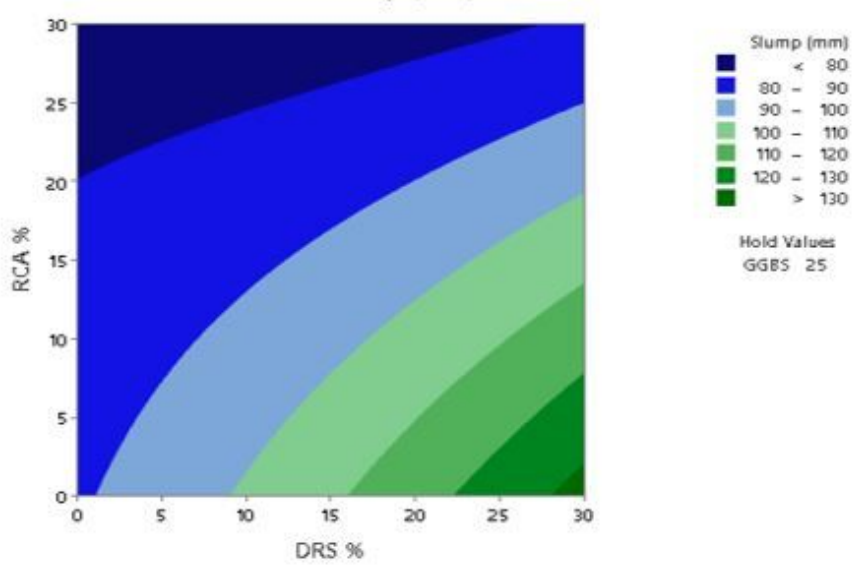

Fig 2 (c)

Figure 2

Contour plot of Slump vs a) RCA, GGBS b) DRS, GGBS c) RCA, DRS 


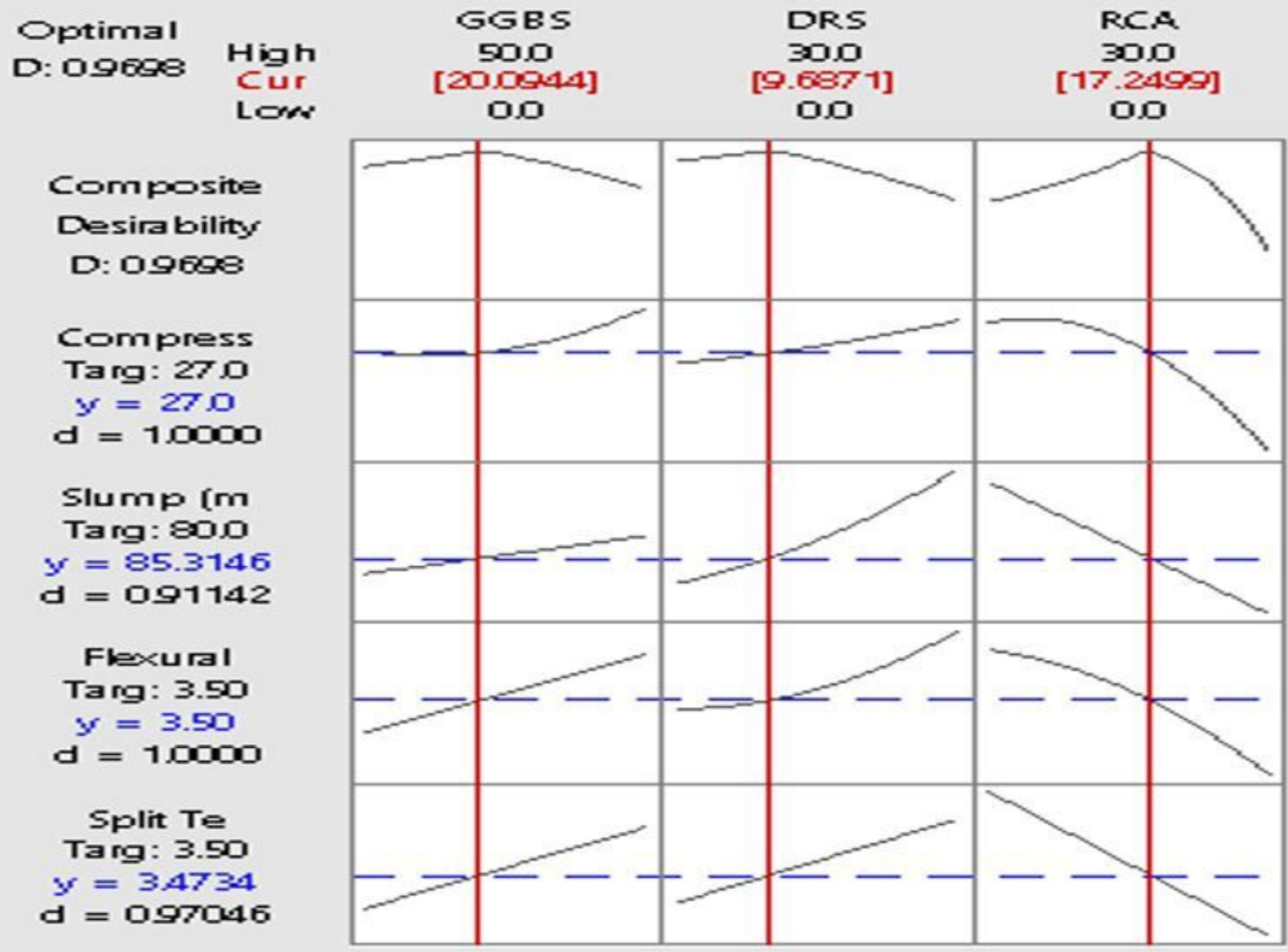

Figure 3

Response optimiser plot

\section{Supplementary Files}

This is a list of supplementary files associated with this preprint. Click to download.

- PrakashDRSSupplementary25.5.21.docx 